\title{
Research on the Optimization about Air-Gap Magnetic Field of AC-Excited Generator
}

\author{
LV Yanling ${ }^{1, \mathrm{a}}$, Chen Wenhai ${ }^{2, \mathrm{~b}}$ and Teng Chong ${ }^{3, \mathrm{c}}$ \\ 1, 2, 3 Harbin University of Science and Technology, Harbin, China \\ ${ }^{a}$ Yanling@163.com, ${ }^{b}$ chenwenhai_haha@163.com, ${ }^{c}$ tc4956410@sina.com
}

\begin{abstract}
Due that the air-gap harmonic wave magnetic field impacts the motor torque property, additional loss and vibration noise, it is critically important to accurately calculate the electromagnetic field, particularly the air-gap magnetic field distribution. On the basis of the research of structure of AC-excited generator, a field-cincuit-motion coupled analysis model for AC-excited generator is established using field-circuit-ntotion coupling method. For investigating the relationship among the air-gap monetic field, slot of rotor, air-gap and width of rotor slot, the distribution diagram of air-gak magnetic field is provided under different states. By harmonic analysis of the air-gap magnetic field of different model, the method to reduce the air-gap larmonic waye magnetic field is proposed. It provides the theoretical support for the optimization design of AC-excited generator.
\end{abstract}

Keywords: AC-excited generatogaty-gap magnetie field; optimized analysis

\section{Introduction}

The three-phase field winding of rotor of AC excitation generator displays a symmetrical distribution /and with three-phase symmetric excitation current. The frequency, amplitude, phase and phase sequence can be controlled [1]. Due to the increase the degrees of freedom of exciation system of AC excitation generator, it can implement variable speed constant frequency. Since it can independently adjust active power and reactive power, the generator can operate under the optimal phase depth and has strong stability [2]. It is found that the plant efficiency of power station can be increased by $10 \%$ with AC excitation generator in investigation of J. Bendl, M. Chomat, L. Schreie. etc. [3].

The air gap harmonic magnetic field of motor is important to the design of motor, the manufactufe of motor and the operation of motor. Not only influence the induction electromotive force, torque characteristics of the motor, additional loss and vibration noise, etc., it is particularly sensitive to noise [4]. The motor running, the air gap harmonie magnetic field mainly includes two parts. The part is built by magnetic potential of rotor winding in air gap. The other part is tooth harmonic magnetic field built by the Magnetic reluctance of air gap changing [5]. The harmonic magnetic field of brushless doubly-fed motor is analyzed and researched and optimization scheme is put forward [6-7].

In traditional motor electromagnetic calculation, because the nonlinear saturation of motor, skin effect and complex boundary shape factors, magnetic circuit method cannot get accurate results[8-9]. On the other hand, because of the complexity of the wire way of the motor end, analysis method is very difficult to achieve [10]. So, using field-circuit coupling method analyzes motor electromagnetic fields, the calculation results can be obtained [11].

In this article, the field-circuit coupling method of AC exciting generator is established, and the air-gap magnetic field of AC exciting generator is analysis on no-load running by using finite element method. Under the influence of rotor trough, the air gap size, and the 
width of the slot, the air gap magnetic field is studied. It puts forward a ways to reduce the air gap magnetic field harmonic content. It provides the reference for further research of structure optimization of AC excitation generator.

\section{The Basic Principle and Structure of AC Excitation Generator}

The stator of AC excitation generator stator is same with traditional synchronous motor, but rotor is different with traditional synchronous motor. The rotor, with three-phase controllable exciting winding, can connect with balanced three-phase alternating current. The stator winding of Ac excitation generator is connected to the electricity grid through transformer. The rotor winding of Ac excitation generator is connected to the grid through energy bi-directional flow excitation converter. It is shown in Figure 1.

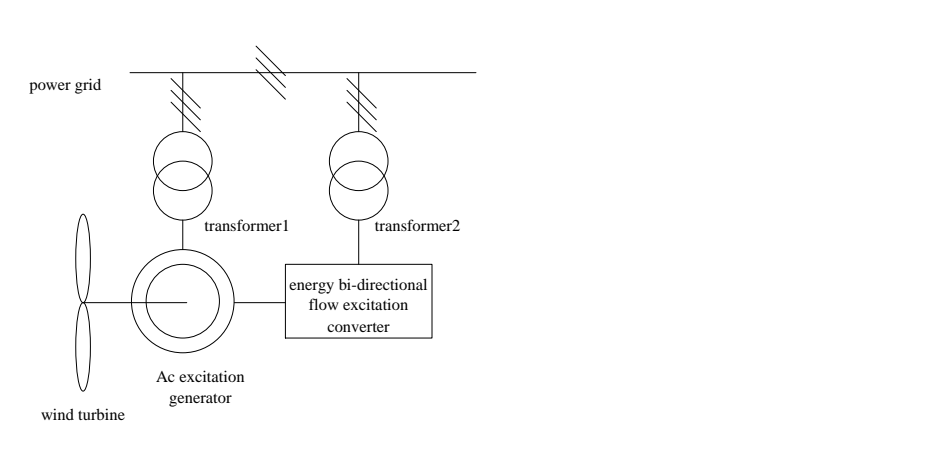

Figure1. Interconnected AC-Excited-Doubly-Fed Wind Power Generator

Ac excitation generator normally working, the stator winding and rotor winding both produce rotating magnetic field. According to the induction rotating magnetic field of stator and rotor is relatively static, $\mathrm{AC}$ excitation generator working, the relations of speed of rotating magnetic field produced by rotor winding to speed of rotating magnetic field produced by stator winding as followb

Use frequency S expressed as.
$f_{1}=\frac{p}{60} n_{r} \pm f_{2}$

Type: $n_{1}$ as rotatign magnetic field rotation speed of the stator; $n_{2}$ as the rotating magnetic field rotafion speed of the rotor; $n_{r}$ as the rotor speed; $f_{1}$ as the frequency of the stator current; $f_{2}$ s the frequency of the rotor current; $p$ as logarithmic of ac excitation generator.

The speed of the AC excitation generator rotor changes with fan. The speed of rotating magnetic field can be adjusted by adjusting the frequency of the exciting current, so that speed of rotating magnetic field is synchronous speed. The purpose of Variable-speed constant-frequency of ac excitation generator is achieved.

\section{The Field-Circuit-Motion Coupling Mode of AC Exciting Generator}

In order to simplify the analysis of this article, emphasize the research question and ensure reasonable computational mathematics model is set up, assumptions as follows:

1) The mode of $\mathrm{AC}$ excitation generator can be divided into linear part and the head part, as shown in Figure 2, 3, head part using the existing analytical calculation method of parameters included in the analysis of branch, the linear part using two-dimensional electromagnetic field finite element analysis.

2) The higher order harmonic component of armature current and vector magnetic potential is ignored, only the effect of fundamental wave is considered.

3) The nonlinear characteristics of rotor material are considered, but the material 
hysteresis loss, the eddy current loss of the motor stator lamination and distortion errors of axial symmetry are ignored.

4) The electrical conductivity of the generator material is constant value.

5) The change of the tooth harmonic is not consider, the cartesian coefficient characterization of the cogging effect gas gap.

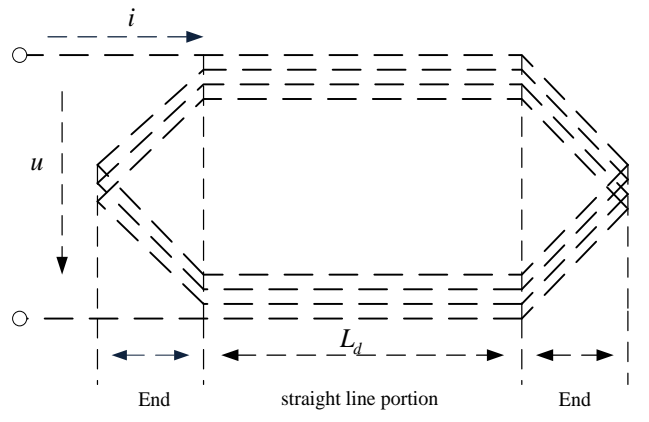

Figure 2. Structure Diagram of Winding Model or AC-Excited Generator

Figure 3. Equivalent Circuit of Winding Model of AC-Excited Generator

The partial differential equation of boundary value problems of the motor transient electromagnetic field can be represented by the type (3) [12], the coupling problem of the electromagnetic fleld and mechanical movement is described

$$
\nabla \times\left(\frac{1}{\mu} \nabla \times A\right)+\sigma\left[\frac{\partial A}{\partial t}-v \times(\nabla \times A)\right]=J
$$

Type: $\mu$ is medum permeability, $A$ is the vector magnetic potential, $\sigma$ is medium conductivity, $\left\{\right.$ is medium velocity relative to the reference coordinate system, $J_{s}$ is the source of externally imposed current density.

\section{The Analysis of Air-Gap Magnetic Field of AC Excitation Generator}

On the small capacity of AC excitation generator, air-gap magnetic field is analysis by using field-circuit coupled method. The main parameters of the generator are as follows: The rated power is $2.2 \mathrm{KW}$. The rated voltage is $220 \mathrm{~V}$. The number of stator slot is 45 . The number of rotor slot is 36 . The number of poles is 6. According to structure parameters of the motor, the field-circuit coupled model of the generator is established. The model is shown in Figure 4.

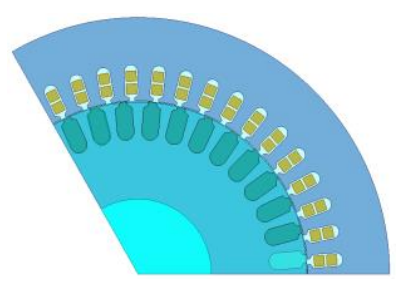


Figure 4. The Model of AC-Excited Generator

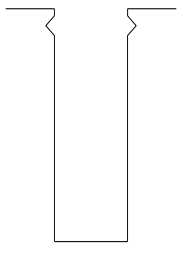

a)

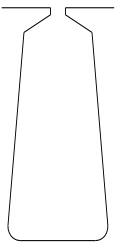

b)

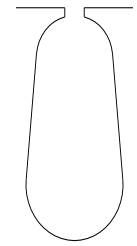

c)
(a) Open Slot
(b) Trapezoidal Slot
(c) Pear-Shaped Slot

\section{Figure 5. Three Different Kinds of Channel}

\subsection{The Air-Gap Magnetic Field under Influence of Rotor Slot Shape}

The rotor slot shape of the motor general has threetypes? open slot, trapezoidal slot, and pear-shaped slot, as shown in Figure 5.As a resul of the differentrotor slot shape, air gap flux density produced by excitation current is not the sarne. Under the premise of the same air gap flux density fundamental wave, it is set up that field-circuit coupled model of ac excitation generator with three differemtrotor slots Analyzing the three models, the three different air-gap flux density of ac excitation generator is obtained, as shown in Figure 6.
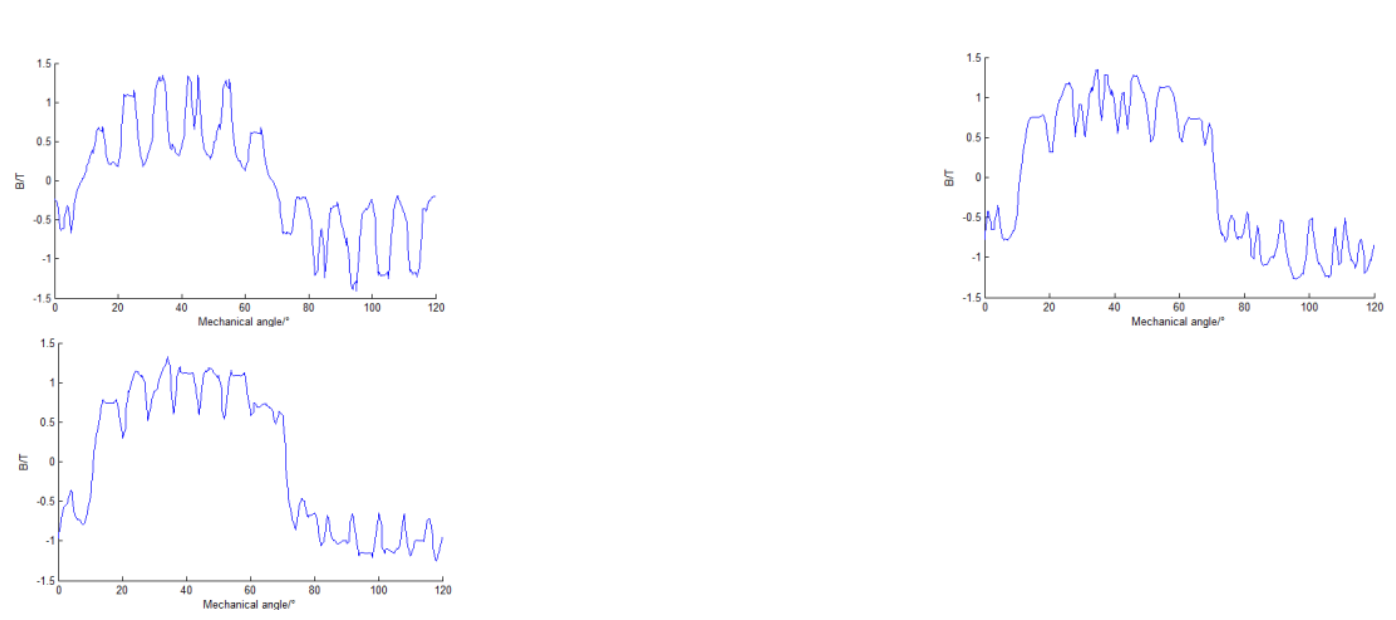

(a) The Air Gap Flux Density of Open Slot (b) The Air Gap Flux Density of Trapezoidal Slot (c) The Air gap Flux Density of Pear-Shaped Slot

Figure 6. Air-Gap Flux Density of AC-Excited Generator with Different Slot of Rotor

As can be seen from the Figure 6, three air-gap flux density of ac excitation generator are non-sinusoidal, because three permeances of air gap the motor are different. The three air-gap flux density in Figure 6 is harmonic analyzed. The variety of harmonic content of air gap flux density is shown in Table 1.

Table 1. Harmonic Content of Harmonic Content of Different Slot of Rotor

\begin{tabular}{c|c|c|c|c|c|c|c}
\hline \multirow{2}{*}{ slot } & \multicolumn{7}{|c}{ The ratio of every harmonic amplitude and the amplitude } \\
\cline { 2 - 8 } & 1 & 5 & 7 & 11 & 13 & 17 & 19 \\
\hline open slot & 100 & 7.735 & 6.686 & 38.290 & 27.882 & 2.039 \\
\hline $\begin{array}{c}\text { trapezoidal } \\
\text { slot }\end{array}$ & 100 & 9.549 & 6.877 & 19.281 & 4.089 & 2.102 & 2.314 \\
\hline
\end{tabular}




\begin{tabular}{c|c|c|c|c|c|c|c}
\hline $\begin{array}{c}\text { pear-shaped } \\
\text { slot }\end{array}$ & 100 & 8.717 & 6.008 & 12.498 & 6.376 & 1.643 & 1.880 \\
\hline
\end{tabular}

As can be seen from Table 1, In the air gap flux density of open slot, the 11 times harmonic component and the 13 times harmonic component are high. In the air gap flux density of trapezoidal slot, the 5 times harmonic component and the 11 times harmonic component are high. In the air gap flux density of pear-shaped slot, the 11 times harmonic component is high. The 11 times harmonic component of pear-shaped slot is less than open slot and pear-shaped slot. Comprehensive consideration, pear-shaped slot is suit as rotor slot the AC excitation generator.

\subsection{The Air-Gap Magnetic Field under Influence of the Air Gap Size}

The size of air gap will also affect the air gap permeance, thus the air gap flux density waveform of $\mathrm{AC}$ excitation generator and the air gap flux density harmonic content is different also. It is set up that field-circuit coupled model of ac excitation generator with three different air gap size. Analyzing the three models the three different air-gap flux density of ac excitation generator is shown in Figure 7

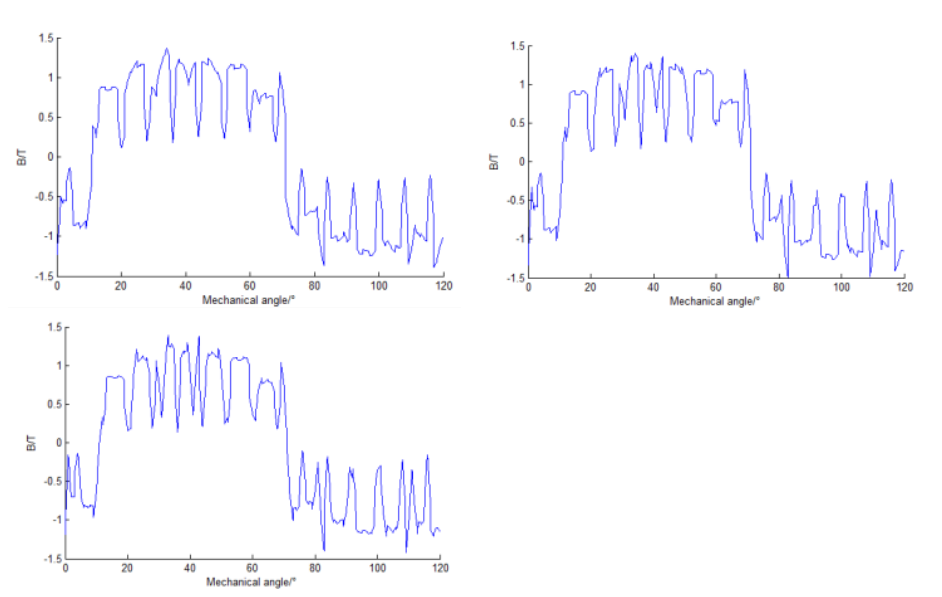
(a) The Air Gap Size is $25 \mathrm{~m}$
(b) The Air Gap Size is $50 \mathrm{~mm}$
(c) The Air Gap Size is
Figure 7. Air-Gap Flux Density of AC-Excited Generator with Different Length of Air-Gap

As can(be seen from the Figure 4, the longer the air-gap size of AC excitation generator, air gap flyx density harmonic content is less. Because of the air gap size affects the air gap permeance, it can offset part the air gap magnetic field waveform caused by rotor slot of the motor. The three air-gap flux density in Figure 7 is harmonic analyzed. The variety of harmonic content of air gap flux density is shown in Table 2.

Table 2. Harmonic Content of Harmonic Content of Different Air Gap Size

\begin{tabular}{c|c|c|c|c|c|c|c}
\hline air gap size & \multicolumn{7}{|c}{ The ratio of every harmonic amplitude and the amplitude } \\
\cline { 2 - 8 }$/ \mathrm{mm}$ & 1 & 5 & 7 & 11 & 13 & 17 & 19 \\
\hline 25 & 100 & 10.998 & 7.830 & 14.292 & 6.600 & 2.498 & 2.889 \\
\hline 50 & 100 & 9.334 & 6.528 & 13.086 & 5.626 & 1.963 & 2.408 \\
\hline 75 & 100 & 8.717 & 6.008 & 12.498 & 6.376 & 1.643 & 1.880 \\
\hline
\end{tabular}

As can be seen from Table 2, In the three air gap flux density of AC generator with different air gap size, the 5 times harmonic component, the 11 times harmonic component, and the 13 times harmonic component are high, especially, the 11 times harmonic component . 
Compared three models, the size of air gap are bigger, and air gap flux density harmonic content is smaller. In order to improve the air gap flux density waveform, the air gap size can be increased in the design of AC excitation generator. Air gap size cannot too big, otherwise the magnetic flux leakage is more, and the efficiency of the motor will be reduced.

\subsection{The Air-Gap Magnetic Field under Influence of the Width of Slot}

The air gap permeance is not only related to channel and air gap length, but also associated with width of rotor slot. The width of the slot of AC excitation generator also affects the air gap flux density waveform. It is set up that field-circuit coupled model of ac excitation generator with three different the width of the slot. Analyzing the three models, the three different air-gap flux density of ac excitation generator is shown in Figure 8.

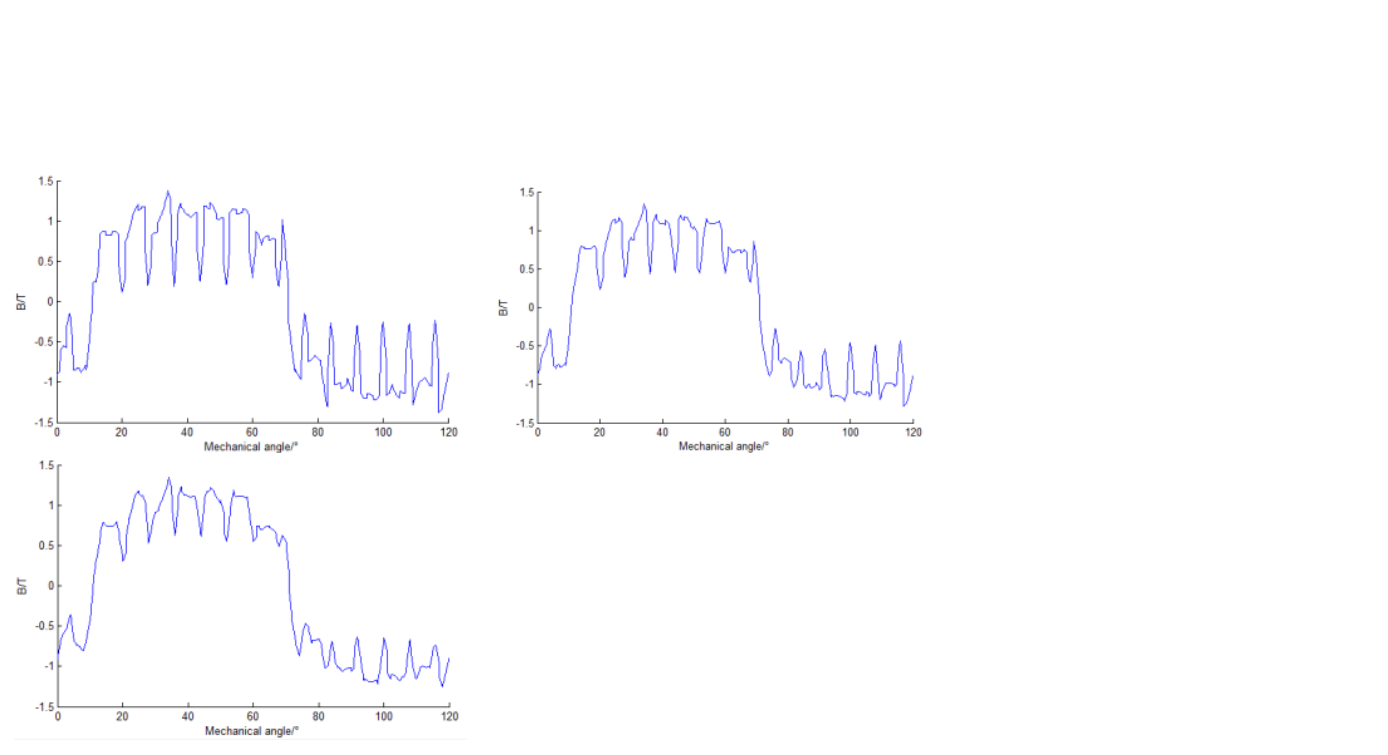

$\begin{array}{llll}\text { (a) The Width of Slot is } 0.5 \mathrm{~mm} & \text { (b) The Width of Slot is } 1 \mathrm{~mm} & \text { (c) The Width of Slot is }\end{array}$

\section{Figure 8. Air-Gap Flux Density of AC-Excited Generator with Different Width of Rotor Slot}

The three air-gap flux density in Figure 8 is harmonic analyzed. The variety of harmonic content of alr gap flux density is shown in Table 3.

As can be seen from Table 3, In the three air gap flux density of AC generator with different the width of slot, the 11 times harmonic component are high, Compared three models and air gap flux density harmonic content is smaller in the width of slot is $0.5 \mathrm{~mm}$. In orden to improve the air gap flux density waveform, the width of slot can be reduced in the design of $\mathrm{AC}$ excitation generator. Because the width of slot is not too small considering wire, the magnetic slot wedge can be used.

Table 3. Harmonic Content of Harmonic Content of Different Width of Rotor Slot

\begin{tabular}{c|c|c|c|c|c|c|c}
\hline \multirow{2}{*}{$\begin{array}{c}\text { width of slot } \\
\text { /mm }\end{array}$} & \multicolumn{7}{|c}{ The ratio of every harmonic amplitude and the amplitude } \\
\cline { 2 - 8 } & 1 & 5 & 7 & 11 & 13 & 17 & 19 \\
\hline 0.5 & 100 & 11.332 & 8.010 & 15.669 & 2.068 & 2.841 & 3.064 \\
\hline 1 & 100 & 11.707 & 8.562 & 18.635 & 6.195 & 3.050 & 3.352 \\
\hline 1.5 & 100 & 12.519 & 9.263 & 19.447 & 2.067 & 3.063 & 3.479 \\
\hline
\end{tabular}

\section{Conclusions}

On the basis of the research of structure of AC-excited generator, a field-circuit-motion 
coupled analysis model for AC-excited generator is established using field-circuit-motion coupling method. Under the influence of rotor trough, the air gap size, and the width of the slot, the air gap magnetic field is studied. We draw a conclusion: 1. The pear-shaped slot is suit as rotor slot the AC excitation generator, which can improve the waveform of air gap flux density. 2. The air gap is longer, the harmonic content of the air gap flux density is less. But air gap size cannot too big, otherwise the magnetic flux leakage is more, and the efficiency of the motor will be reduced. 3. Magnetic slot wedge can improve the waveform of air gap flux density, which can reduce the wastage, noise and vibration of the $\mathrm{AC}$ excitation generator.

\section{Acknowledgement}

Project supported by the National Natural Science Foundation of China (5140070496).

\section{References}

[1] Y. Shunchang, L. Yong, L. Hui and X. Dawei, "Asynchronous generators, Beijing: Science Press, (2009).

[2] Z. Haihong, X. Liqun and Y. Xiangwu, "Review on asynehronous generators under synchronous operation mode", North China Electric Power, vol. 25, no 10, (2000)

[3] J. Bend, M. Chombt and L. Schreier, "Adjustable-speed Operation of Doubly Fed Machines in Pumped Storage Power Plants", Ninth International Conference on Electrical Machines and Drives, (conf. Publ. No. 468), (1999).

[4] H. Li, W. Hua and M. Nianping, "Calculation and analysis of harmonic copper losses and iron losses of brushless doubly-fed machine", Electric Machines and Control) vol. 16, no. 3, (2012).

[5] B. Heller, "Effect of harmonic magnetic field on asynehronous motor", Beijing: China Machine Press, (1980).

[6] Y. Xiangyu and C. Xiaoming, Harmonic magnetic field analysis of brushless Doubly-Fed machines for adjustable speed drives", Journal of South China University of Technology, vol. 33, no. 4, (2005).

[7] Z. Lingjuan, "Investigation on the harmonic field analysis of brushless Doubly-Fed machines", Zhejiang: Zhejiang University, (2013)

[8] M. Dawei and L. PAngzhou, "Design and research of 1MW high slip wound asynchronous wind generator", Journal of Haerbin University of Science and Technology, vol. 4, no. 16, (2011).

[9] S. L. Ying M. D. Wei and L. Y Bo, "Application of mutually related field-circuit method steady-state analysis of saljent pole synchronous machine", Journal of Haerbin University of Science and Technology, vol. 8, no. 6. (2003).

[10] L. Ruifang, Y. Dengjun and H. Minqiang, "Field circuit and movement coupled time stepping finite element analysis on permanent magnet brushless DC motors", Proceeding of the CSEE, vol. 27, no. 12, (2007).

[11] Y. Xiuke, "Field-Circuit-Motion coupled analysis for switched reluctance motor", Beijing: Shenyang University of Technology, (2004).

[12] H. Minqlang and H. Xueliang, "Numerical computation method of electric machine performance and its application", Nanjing: Publishing House of Southeast University, (2003). 
International Journal of Multimedia and Ubiquitous Engineering

Vol.11, No.2 (2016)

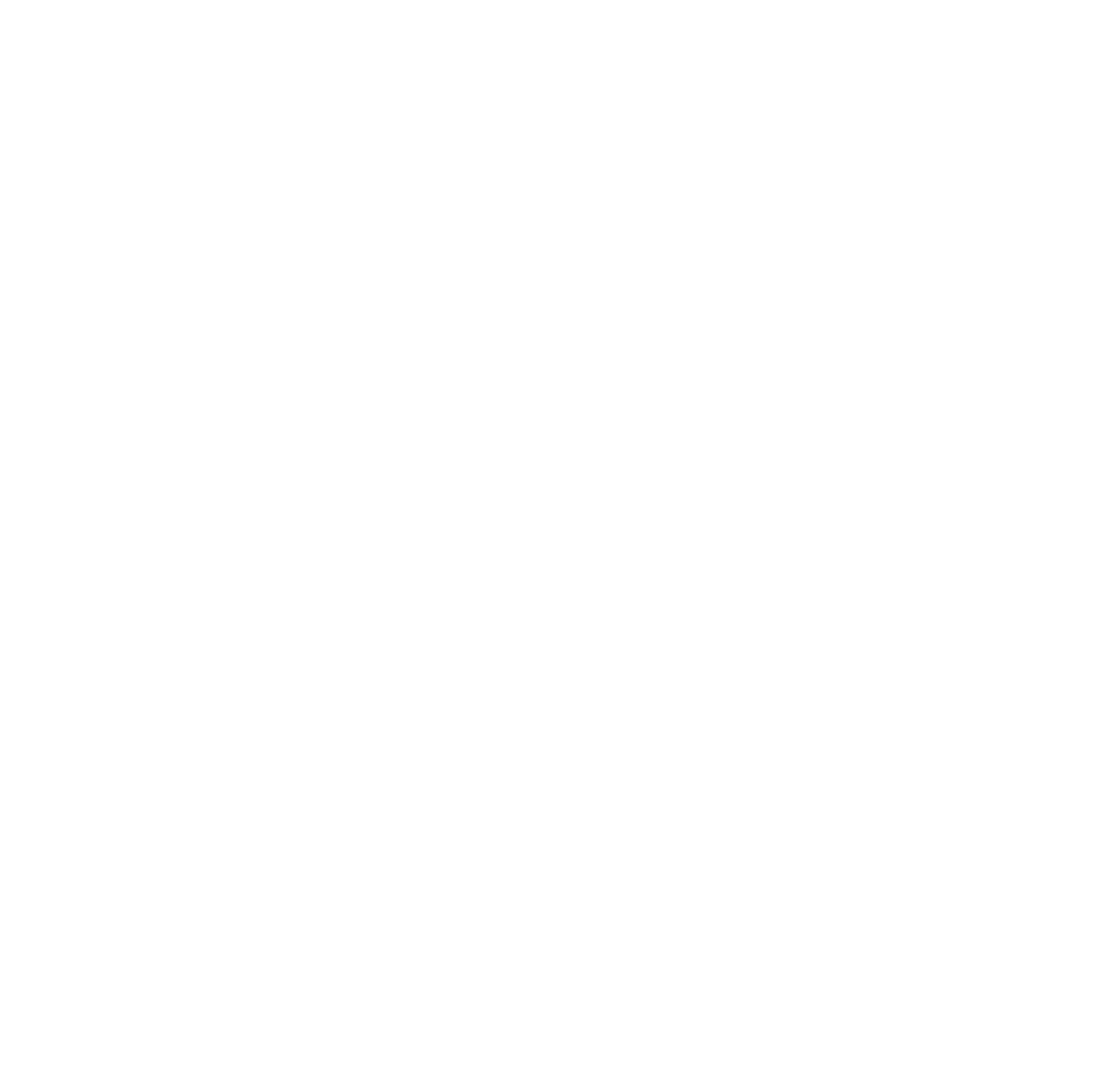

